\title{
Análise das Demonstrações Contábeis e Indicadores Sociais da Companhia Estadual de Energia Elétrica (CEEE-GT)
}

\author{
Cybele Troina do Amaral ${ }^{1}$ \\ João Eduardo Prudêncio Tinoco ${ }^{2}$ \\ José Alberto Carvalho dos Santos Claro ${ }^{3}$ \\ Daiane Pias Machado 4 \\ Vanessa de Quadros Martins ${ }^{5}$
}

\section{Resumo}

O objetivo desta pesquisa consistiu em analisar o desempenho econômico, financeiro, socioambiental da CEEE-GT no período de 2008 a 2011. Trata-se de um estudo exploratório, com análise descritiva e enfoque qualitativo do problema. Analisaram-se as Demonstrações Contábeis, o Relatório da Administração e o Balanço Social, coletados nos sítios da Bolsa de Valores de São Paulo e da CEEE. Apresentou desempenho econômico e financeiro satisfatório, de acordo com indicadores evidenciados. A estrutura de capital é boa, tendo em vista a prevalência do capital próprio sobre o de terceiros. Observou-se piora nos resultados de rentabilidade, tanto no que se refere ao retorno do Patrimônio Líquido, como no que tange ao Retorno do Ativo Ajustado. Em 2008 o retorno do PL atingiu 21\%, decaindo para 4\% em 2011, enquanto que o Retorno do Ativo passou de 9\% em 2008, para 3\% em 2011. A empresa gerou valor adicionado líquido de $\mathrm{R} \$ 640.227$ milhões em 2011, sendo que coube $40 \%$ desse montante aos colaboradores. Na análise dos indicadores do Balanço Social no ano de 2011, destacam-se as aplicações nos elementos sociais externos de $65 \%$ do resultado operacional. Os indicadores sociais internos representam $46 \%$ da folha de pagamento bruta.

Palavras-chave: Análise financeira. Indicadores de desempenho. Indicadores socioambientais.

\section{Analysis of Financial Statements and Social Indicators of the Companhia Estadual de Energia Elétrica (CEEE-GT)}

\footnotetext{
Abstract

The objective this research consisted in analyze the economic, financial, social and environmental CEEE-GT in the period 2008 to 2011. This is an exploratory study with a

${ }^{1}$ Filiação: Servidora da Universidade Federal do Rio Grande - FURG e mestranda do Programa de Pós-Graduação em Ciências Contábeis da Universidade do Vale do Rio dos Sinos - UNISINOS. e-mail: cyta@,ig.com.br

${ }^{2}$ Professor do Programa de Pós-Graduação em Ciências Contábeis Doutorado e Mestrado da Universidade do Vale do Rio dos Sinos - UNISINOS. E-mail: tinocojoao@uol.com.br

${ }^{3}$ Professor Doutor da Universidade Metodista de São Paulo. E-mail:

4 Filiação: Docente da Universidade Federal do Rio Grande - FURG e mestranda do Programa de Pós-Graduação em Ciências Contábeis da Universidade do Vale do Rio dos Sinos - UNISINOS. e-mail:

daianepiasmachado@yahoo.com.br.E-mail: profalbertoclaro@gmail.com

${ }^{5}$ Filiação: Servidora da Universidade Federal do Rio Grande - FURG e mestranda do Programa de Pós-Graduação em Ciências Contábeis da Universidade do Vale do Rio dos Sinos - UNISINOS. e-mail: vanessa_qm@yahoo.com.br
} 
qualitative and descriptive analysis of the problem. It was analyzed the financial statements, the Management Report and Social Report, collected on the websites of the Stock Exchange of São Paulo and CEEE. Presented satisfactory economic and financial performance, according to indicators evidenced. The capital structure is good in view of prevalence of equity to third. There was notice deterioration in profitability results both in terms of return on equity, as in respect to Adjusted Return on Assets. In 2008 the return of NE was 21\%, decreasing 4\% in 2011, while the Return on Assets increased from 9\% in 2008 to 3\% in 2011. The company generated net added value of $\mathrm{R} \$ 640,227$ million in 2011 , and $40 \%$ of this amount fitted to employees. In the analysis of the Social Indicators in 2011, there are the social elements in the external applications of $65 \%$ of operating profit. The internal social indicators account for $46 \%$ of gross payroll.

Keywords: Financial analysis. Performance indicators. Social environmental indicators.

\section{INTRODUÇÃO}

O fornecimento de energia elétrica no Brasil é uma prerrogativa da União, conforme art.21 da Constituição Federal (Brasil, 1988):

Art.21. Compete à União:

(...) XII - explorar, diretamente ou mediante autorização, concessão ou permissão:

(...) b) os serviços e instalações de energia elétrica e o aproveitamento energético dos cursos de água, em articulação com os Estados, onde se situam os potenciais hidroenergéticos.

No Estado do Rio Grande do Sul, área de atuação da empresa pesquisada, a prestação de serviço público de geração e transmissão de energia elétrica ocorre em regime de concessão estabelecido em contrato assinado entre a Companhia Estadual de Energia Elétrica - CEEE e a Agência Nacional de Energia Elétrica - ANEEL.

Castro e Lyra Filho (2005, s.p.) colocam que

por muitos anos, os economistas defenderam que a energia elétrica era um monopólio natural, pois do ponto de vista da racionalidade econômica, pelo fato da transmissão e distribuição representarem elevados investimentos, estes sistemas não são construídos simultaneamente por dois agentes que concorrem pelo atendimento à mesma parcela de mercado. Mais recentemente, a percepção de que é possível a competição entre os agentes na área de produção e comercialização da energia, mantendo-se o monopólio natural apenas nas áreas de transmissão e distribuição (Davidison et al, 2002) permitiu que as leis de mercado passassem a permear o serviço público de energia elétrica. 
O Grupo CEEE atua no setor energético nos segmentos de geração, transmissão, distribuição e comercialização de energia elétrica, além de serviços correlatos. Está presente em todo o Estado do Rio Grande do Sul (RS), onde possui suas operações, gerenciando seus negócios diretamente ou através da participação em outras sociedades de capital intensivo e tecnologia de ponta.

Criada em 1943, a CEEE foi a precursora das empresas que hoje compõem o Grupo CEEE. Da reestruturação societária da CEEE, ocorrida em 2006, originaram-se:

- A Companhia Estadual de Energia Elétrica Participações - CEEE-Par;

- A Companhia Estadual de Geração e Transmissão de Energia Elétrica - CEEE-GT; e,

-A Companhia Estadual de Distribuição de Energia Elétrica - CEEE-D.

A CEEE-GT é uma sociedade anônima de capital aberto, sendo seu acionista controlador o Estado do Rio Grande do Sul, através da Companhia Estadual de Energia Elétrica Participações - CEEE-Par, empresa detentora de $65,92 \%$ do seu capital total, caracterizando, portanto, uma sociedade de economia mista.

A CEEE Geração e Transmissão é a responsável pela maioria das instalações que compõem a Rede Básica de Transmissão do Estado, viabilizando o transporte e suprimento de energia às Concessionárias de Distribuição que atuam no RS: CEEE Distribuidora, AES Sul, RGE, Concessionárias Municipais, Cooperativas de Eletrificação Rural e também a potenciais Consumidores Livres e Produtores Independentes.

Atualmente a CEEE-GT, segundo a Melhores e Maiores de 2012 da Revista Exame, por faturamento líquido é a $535^{\mathrm{a}}$ maior empresa do Brasil, ocupando o $79^{\mathrm{a}}$ posição na Região Sul. É responsável pela produção de 75\% da energia hidrelétrica gerada no Estado (CEEE, 2012).

Tendo em vista pesquisar e evidenciar o desempenho econômico, financeiro, social e ambiental da empresa verifica-se que a Contabilidade surge como estratégia para estabelecer canal de evidenciação com a sociedade, permitindo identificar, mensurar e analisar os eventos econômicos, financeiros e socioambientais, divulgando-os aos parceiros sociais, como explicitam Carneiro, De Luca e Oliveira (2008).

Diante do exposto, surge o seguinte problema de pesquisa: dado o destaque da CEEE-GT, qual o desempenho econômico, financeiro, social e ambiental da empresa no período de 2008 a 2011, evidenciado por seus indicadores contábeis, econômicos e socioambientais? 
Portanto, o objetivo geral dessa pesquisa é analisar e evidenciar seus desempenhos econômico, financeiro, social e ambiental da no período de 2008 a 2011.

Os objetivos específicos que contribuirão para o alcance do objetivo geral são:

- Analisar as Demonstrações Contábeis em conjunto com o Relatório de Administração;

- Analisar o Balanço Social.

A presente pesquisa justifica-se pela representatividade do setor de energia elétrica na economia do Estado, em que a CEEE - GT atua, pois produz $75 \%$ da energia elétrica do mercado gaúcho. Além de seu caráter econômico, desenvolve junto aos seus consumidores diversos projetos sociais, culturais e ambientais, tornando-se relevante o desenvolvimento de pesquisas neste tipo de empresa.

O artigo está estruturado em mais quatro seções, apresentando-se na segunda seção o referencial teórico bem como o perfil da empresa analisada. Na terceira seção está o delineamento metodológico da pesquisa. Na quarta seção estão dispostas a análise dos dados e a discussão dos resultados alcançados e, por fim, na quinta seção, apresentam-se os argumentos conclusivos da pesquisa.

\section{REVISÃO BIBLIOGRÁFICA}

No que tange aos pesquisadores que vem estudando a análise das demonstrações contábeis incorporando a abordagem socioambiental destacam-se: Assaf Neto (2010), Matarazzo (2010), Martins (1997), Iudícibus et al (2010), Santos (2003), Ribeiro (1992), Tinoco (1984 e 2010) e Warren, Reeve e Fess (2008).

Warren, Reeve e Fess (2008, p. 522) consideram que "as demonstrações financeiras básicas fornecem muitas das informações de que os usuários necessitam para tomarem decisões econômicas sobre negócios.". Sendo assim, analisar o conjunto de informações constantes nas demonstrações contábeis é essencial para a boa gestão empresarial.

Para Sant'anna et al. (2011, s.p.)

a análise de balanços visa relatar, com base nas informações contábeis fornecidas pelas empresas, a posição econômico-financeira atual, as causas que determinaram a evolução apresentada e as tendências futuras. Em outras 
palavras, pela análise de balanços extraem-se informações sobre a posição passada, presente e futura (projetada) de uma empresa.

A análise das demonstrações contábeis divide-se basicamente em duas fases, a primeira é denominada Análise Tradicional, que envolve as análises vertical e horizontal das demonstrações contábeis. As análises vertical e horizontal proporcionam uma visão geral da empresa em termos de evolução patrimonial e relevância dos elementos patrimoniais. Matarazzo (2010, p. 171) considera que a análise vertical "baseia-se em valores percentuais das demonstrações financeiras. Para isso se calcula o percentual de cada conta em relação a um valor-base.” Já a análise horizontal, o autor considera que evidencia a evolução das contas ao longo de um período, tomando por base o ano mais antigo da série.

A segunda fase da análise das demonstrações ocorre com base em indicadores financeiros e econômicos.

Os indicadores financeiros e econômicos são formados pela análise por quocientes utilizada como parâmetro de avaliação da influência ou da proporção de um elemento sobre outro. É um tipo de análise adotado usualmente no estudo da capacidade financeira da empresa e da rentabilidade do investimento. (SANT'ANNA et al., 2011, s.p.).

Afirma-se, assim, que a comparação dos indicadores financeiros e econômicos é o critério básico que norteia a análise de balanços (ASSAF NETO, 2010). Matarazzo (2010) elenca um conjunto de índices distribuídos entre Estrutura de Capital, Liquidez e Rentabilidade. Fazem parte dos índices de Estrutura de Capital: participação de capitais de terceiros, composição do endividamento, imobilização do patrimônio líquido, imobilização dos recursos não correntes. Os índices de Liquidez abrangem: liquidez geral, liquidez corrente e liquidez seca. Já os índices de Rentabilidade dividem-se em: giro do ativo, margem líquida, rentabilidade do ativo e rentabilidade do patrimônio líquido. Além desses, o autor complementa a análise das demonstrações com os índices de Prazos Médios, sendo eles: recebimento de vendas, pagamento de compras e renovação de estoques, os quais proporcionam uma visão dos Ciclos Operacional e Financeiro. Além da análise tradicional e de indicadores financeiros e econômicos, atualmente, tem ganhado destaque a análise de indicadores sociais e ambientais fundamentados no Balanço Social. Tinoco (2010, p. 29) descreve que o Balanço Social, ou Relatório Socioambiental, ou ainda Relatório de Sustentabilidade, "tem por ambição descrever certa realidade econômica, 
social e ambiental de uma entidade (empresa, governos, ONGs), através do qual é suscetível de avaliação".

Pinto e Ribeiro (2004) expõem que o objetivo principal do balanço social é demonstrar o resultado da interação da empresa com o meio em que está inserida, no qual devem ser observados, principalmente, os recursos humanos, os aspectos econômico e social, ambiental e contribuições para a cidadania. O Balanço Social possui indicadores que também contribuem com sua análise, dentre eles destacam-se: indicadores de gestão de pessoas, indicadores econômicos de desempenho, indicadores ambientais, indicadores sociais, indicadores de sustentabilidade.

No contexto do Balanço Social, existe a Demonstração do Valor Adicionado (DVA), que é uma vertente desse Balanço. A DVA passou a ser obrigatória após a alteração da Lei das Sociedades Anônimas, Lei n ${ }^{o}$ 6.404/76, por meio da Lei $n^{\circ} 11.638 / 07$, que em seu artigo 176, inciso $\mathrm{V}$, estabelece a obrigatoriedade da publicação da demonstração do valor adicionado, para as companhias abertas. O artigo 188, inciso II define ainda que a demonstração do valor adicionado deverá indicar, no mínimo, o valor da riqueza gerada pela companhia, a sua distribuição entre os elementos que contribuíram para a geração dessa riqueza, tais como empregados, financiadores, acionistas, governo e outros, bem como a parcela da riqueza não distribuída (BRASIL, 1976; 2007). Neste sentido,

DVA é uma explanação de como a empresa criou riquezas (valor de suas vendas de bens e serviços deduzidos dos bens e serviços adquiridos de terceiros) e como a distribuiu entre: fornecedores de capital, recursos humanos e governo. Vê-se, então, à parte da riqueza criada que cabe aos primeiros na forma de financiadores (via juros e aluguéis), de sócios (via dividendos e lucros retidos) e de detentores de tecnologia (via royalties); aos de recursos humanos via seus salários, gratificações, honorários, participações nos resultados etc. e, finalmente, ao governo via impostos, diretos e indiretos. Extraordinária forma de ver a função social da empresa, além de qual a sua parcela na criação da riqueza global do País, o PIB, em vez de só dar tanta ênfase à linha final da demonstração do resultado tradicional, de interesse exclusivo dos proprietários (MARTINS, 1997, p. A-3).

Ademais, Tinoco (2010, p. 85) observou que:

uma das formas que ampliam a capacidade de se analisar o desempenho econômico e social das organizações é através do valor econômico que é 
agregado aos bens e serviços adquiridos de terceiros, valor esse denominado de Valor Adicionado ou Valor Agregado (valor total da produção de bens e serviços de um determinado período, menos o custo dos recursos adquiridos de terceiros, necessários a esta produção), bem como a forma pela qual este está sendo distribuído entre os diferentes grupos sociais que interagem com suas atividades.

Pelas palavras de De Luca (1998, p. 33), a DVA evidencia "o quanto de valor a empresa adiciona aos insumos que adquire, bem como sua distribuição entre os elementos que contribuíram para essa adição", ao contrário das demais demonstrações que estão preocupadas na evidenciação do lucro. Santos (2003) expõe a importância em se elaborar a DVA, tendo em vista o papel que exerce no cálculo de indicadores sociais e sua utilidade ao apresentar a contribuição da empresa com a sociedade. A DVA permite que seja feito um mapeamento de como a riqueza gerada foi distribuída para seus empregados, governo, financiadores externos e sócios ou acionistas (CUNHA; RIBEIRO; SANTOS, 2005).

Conceitualmente, a DVA é uma das peças do Balanço Social, todavia, tem vida própria e é apresentada em conjunto com as outras demonstrações contábeis usuais. Para Iudícibus et al. (2010) a DVA tem como propósito a transparência da contribuição da empresa para o desenvolvimento econômico-social da região onde está instalada e deve discriminar o que a empresa agrega e distribui a riqueza à economia local. Ribeiro (1992, p. 61) considera que "O conceito de responsabilidade social envolve o conhecimento das preferências e prioridades sociais". Melo Neto e Froes (2001, p. 26) destacam que "a ação de responsabilidade social não é individual. Reflete a ação de uma empresa em prol da cidadania".

\section{METODOLOGIA}

O presente estudo possui objetivos descritivos. Conforme Gil (1999), esse tipo de pesquisa objetiva descrever as características de determinada população ou fenômeno. Quanto aos procedimentos, trata-se de um estudo de caso. Raupp e Beuren (2006) consideram que esse tipo de procedimento ocorre mediante o estudo de um único caso, e que é preferido pelos pesquisadores que desejam aprofundar seus conhecimentos a respeito de um caso específico. A abordagem do problema é de cunho qualitativo, pois não utiliza métodos estatísticos na análise dos dados. Gil (1999) considera que a diferença entre um estudo qualitativo e um quantitativo é 
que no qualitativo não há o emprego de ferramentas estatísticas.

Para alcançar os objetivos gerais do estudo, analisaram-se as Demonstrações Contábeis em conjunto com o Relatório da Administração da CEEE-GT e seu Balanço Social, no período de 2008 a 2011. Para tanto, a coleta dos dados ocorreu nos sítios da Bolsa de Valores de São Paulo (BMF\&BOVESPA) e da CEEE. Primeiramente, evidenciaram-se os indicadores específicos do setor de energia elétrica alcançados pela CEEE-GT. Em seguida, procedeu-se a análise tradicional do Balanço Patrimonial e da Demonstração do Resultado do Exercício, por meio da análise vertical e horizontal. Posteriormente analisaram-se os índices econômicos e financeiros dessas demonstrações. Por fim, procedeu-se a análise dos indicadores socioambientais.

\section{ANÁLISE DOS RESULTADOS}

Nessa seção apresentam-se os resultados obtidos mediante a análise e evidenciação do conjunto de Demonstrações Contábeis e do Balanço Social da CEEE-GT, bem como de indicadores de desempenho operacional e de produtividade próprios da CEEE-GT.

\subsection{Indicadores de Desempenho Operacional e de Produtividade da CEEE-GT}

A CEEE-GT utiliza uma série de indicadores que permitem o monitoramento da energia gerada e do desempenho do Sistema Elétrico de Transmissão do Rio Grande do Sul, facilitando a canalização de recursos para buscar melhores índices, melhor qualidade e o mínimo possível de interrupções. Esses indicadores estão evidenciados no relatório da administração da empresa.

\subsubsection{Indicadores da área de Geração}

\section{$\checkmark$ Disponibilidade}

As usinas hidrelétricas devem possuir mensalmente disponibilidade móvel de energia nos últimos 60 meses igual ou superior à estabelecida pela ANEEL para o ano de 2011 (ANEEL, 2012). As Usinas Hidrelétricas (UHE's) que alcançaram a disponibilidade de energia estabelecida pela ANEEL encontram-se na Tabela 1:

Tabela 1: Disponibilidade Móvel de Energia das UHE's

\begin{tabular}{l|c|c}
\hline $\begin{array}{c}\text { Usina } \\
\text { (UHE's) }\end{array}$ & $\begin{array}{c}\text { Referência (limite } \\
\text { inferior) ANEEL }\end{array}$ & $\begin{array}{c}\text { Resultado } \\
\text { (dez/2011) }\end{array}$ \\
\hline Itaúba & $89,58 \%$ & $92,61 \%$ \\
\hline
\end{tabular}

ReFAE - Revista da Faculdade de Administração e Economia, v. 4, n. 2, p. 2-24, 2013 


\begin{tabular}{l|c|c}
\hline Passo Real & $89,58 \%$ & $93,34 \%$ \\
\hline Leonel de Moura Brizola & $93,01 \%$ & $96,47 \%$ \\
\hline
\end{tabular}

Fonte: Relatório da Administração da CEEE-GT do ano de 2011.

Conforme demonstrado na Tabela 1, apenas três das quinze usinas alcançaram a disponibilidade móvel de energia estabelecida pela ANEEL, as demais UHE's não atingiram o referido limite.

\section{$\checkmark$ Produção de Energia}

A CEEE estabelece como meta de produção de energia atingir $100 \%$ da garantia física vigente para cada UHE's e PCH's, na média anual. Na Tabela 2 estão dispostas as metas alcançadas por cada unidade.

Tabela 2: Meta Alcançada por Unidade

\begin{tabular}{l|c|c}
\hline & Meta de Geração (\%) & Energia Gerada (\%) \\
\hline Usinas (UHE's) & & \\
\hline Itaúba & 100 & 113,73 \\
\hline Leonel de Moura Brizola & 100 & 119,23 \\
\hline Passo Real & 100 & 136,16 \\
\hline Canastra & 100 & 97,35 \\
\hline Ernestina & 100 & 93,39 \\
\hline Pequenas Centrais Hidrelétricas (PCH's) & & 112,64 \\
\hline Toca & 100 & 119,46 \\
\hline Capigui & 100 & 109,48 \\
\hline Forquilha & 100 & 140,53 \\
\hline Guarita & 100 & 103,25 \\
\hline Ijuizinho & 100 & 133,90 \\
\hline Santa Rosa & 100 & 97,67 \\
\hline Bugres & 100 & 5,60 \\
\hline Herval & 100 & 97,07 \\
\hline Passo do Inferno & 100 & 58,94 \\
\hline Ivaí & 100 & \\
\hline Font Relatorian
\end{tabular}

Fonte: Relatório da Administração da CEEE-GT do ano de 2011.

O Relatório da Administração a CEEE relaciona alguns fatos com as metas não atingidas por algumas unidades:

- UHE Canastra, PCH Bugres e PCH Passo do Inferno a ocorrência de período de estiagem nos últimos meses do ano, onde a falta de chuvas acarretou na 
diminuição considerável do nível das barragens que alimentam estas centrais geradoras.

- PCH Herval e PCH Ivaí encontram-se em processos de manutenções prolongadas no ano de 2011.

\section{$\checkmark$ Taxa de crescimento e de Garantia Física}

A Taxa de Crescimento mensura a variação percentual da capacidade de geração de energia elétrica. Em 2011 a meta estabelecida era de 4,07\%, no entanto a CEEE obteve uma taxa de crescimento de 2,09\%, sendo $1,98 \%$ inferior à meta estabelecida.

O controle do crescimento da Taxa de Garantia Física é realizado de forma anual através da contabilização dos valores de energia assegurada adicionadas ao parque gerador da empresa. Em 2011 a meta estabelecida era de 4,11\%, no entanto o resultado alcançado foi de $1,71 \%$, sendo $2,4 \%$, inferior à meta estabelecida.

\subsubsection{Indicadores de Transmissão Operacionais e de Produtividade}

\section{$\checkmark$ Capacidade Instalada}

Este indicador corresponde à soma da potência nominal de todos os transformadores da Transmissão em operação. Em 2011 a CEEE-GT teve seis obras concluídas e energizadas, aumentando em 302 MVA a potência instalada ao sistema de transmissão, totalizando 8.346 MVA. Houve um aumento de 3,75\% de capacidade instalada em relação a 2010. Os principais empreendimentos que entraram em operação comercial e proporcionaram esse aumento na capacidade instalada foram nas subestações de Santa Cruz 1, Quinta e Scharlau.

Índice de Indisponibilidade Mensal de Energia (IIT) 
Esse índice indica o percentual de energia deixada de transportar no mês, em relação ao montante total de energia requerida. Na Tabela 3 estão descritos os percentuais de energia deixada de transportar no mês.

Tabela 3: Energia Deixada de Transportar

\begin{tabular}{l|c|c|c|c}
\hline \multicolumn{1}{c|}{ Indicador } & $\mathbf{2 0 0 9}$ & $\mathbf{2 0 1 0}$ & $\mathbf{2 0 1 1}$ & Média 2006/2010 \\
\hline IIT - Geral (\%) & 0,0057 & 0,0060 & 0,0071 & 0,0093 \\
\hline IIT -Transmissão (\%) & 0,0055 & 0,0039 & 0,0060 & 0,0076 \\
\hline
\end{tabular}

Fonte: Relatório da Administração da CEEE-GT do ano de 2011.

Verifica-se uma estabilidade destes indicadores entre 2009 e 2011 e uma queda significativa em relação à média verificada nos últimos 5 anos (2006 a 2010), sinalizando o acerto dos investimentos da transmissão, pois quanto menor o indicador, melhor o resultado.

Dentre as causas mais comuns de interrupção no transporte de energia apontadas pela CEEE estão: desligamentos programados; fenômenos naturais e ambientais; falhas humanas; falhas de equipamentos de potência; falhas de equipamentos de proteção e controle; entre outras.

\section{$\checkmark$ Energia Deixada de Transmitir (Energia Interrompida no mês em Mega Watts hora - MWh)}

Esse índice indica a energia deixada de transmitir, em relação ao montante total de energia requerida. Na Tabela 4 descrevem-se essas informações.

Tabela 4: Energia Deixada de Transmitir

\begin{tabular}{l|c|c|c|c|c}
\hline \multicolumn{1}{c|}{ Indicador } & $\mathbf{2 0 0 8}$ & $\mathbf{2 0 0 9}$ & $\mathbf{2 0 1 0}$ & $\mathbf{2 0 1 1}$ & Média 2006/2010 \\
\hline EDT Total - Geral (MWh) & $3.255,67$ & $1.589,09$ & $1.866,11$ & $2.217,98$ & $2.568,24$ \\
\hline EDT Total - Transmissão (MWh) & $2.317,39$ & $1.538,44$ & $1.206,78$ & $1.885,27$ & $2.079,39$ \\
\hline EDT Média - Geral (MWh) & 271,31 & 132,42 & 155,51 & 184,83 & 214,02 \\
\hline EDT Média - Transmissão (MWh) & 193,12 & 128,2 & 100,56 & 157,11 & 173,28 \\
\hline
\end{tabular}

Fonte: Relatório da Administração da CEEE-GT do ano de 2011.

Legenda:

EDT Total: montante de toda a energia interrompida no ano.

EDT Média: é a média nos doze meses do ano.

Geral: motivos externos e alheios a CEEE Transmissora.

Transmissão: causas específicas de responsabilidade de CEEE Transmissora.

No Relatório da Administração a CEEE-GT destaca que o crescimento da EDT do ano 2011 em relação a 2010 foi fortemente influenciado por duas ocorrências com causas específicas, 
as quais provocaram cerca de $20 \%$ da EDT do ano, que foram:

1) Ocorrência do dia 05/01/2011 ocasionada por vegetação em área de preservação permanente sob as Linhas de Transmissão 230kV Gravataí 2 / Porto Alegre a qual afetou o atendimento a Porto Alegre, provocando uma EDT de 209 MWh.

2) Ocorrências nos dias 29/07/11 e 27/10/11 com o desarme das linhas de transmissão LTs 69kV Lajeado2 / Lajeado1 as quais interromperam 174 MWh.

\subsection{Demonstrações Contábeis}

A seguir apresentam-se, as Tabelas 5 e 6, relativas aos Balanços Patrimoniais e Demonstrações de Resultados dos Exercícios, do período de 2008 a 2011 da CEEE-GT, já considerando as reclassificações necessárias.

Tabela 5: Balanços Patrimoniais da CEEE-GT, período de 2008-2011. Milhão de Reais.

\begin{tabular}{|c|c|c|c|c|c|c|c|c|c|c|c|c|}
\hline $\begin{array}{l}\text { Balanço } \\
\text { Patrimonial }\end{array}$ & 2011 & $\begin{array}{c}\mathrm{AV} \\
\%\end{array}$ & $\begin{array}{c}\text { AH } \\
\%\end{array}$ & 2010 & $\begin{array}{c}\text { AV } \\
\% \\
\end{array}$ & $\begin{array}{c}\mathbf{A H} \\
\%\end{array}$ & 2009 & $\begin{array}{c}\text { AV } \\
\% \\
\end{array}$ & $\begin{array}{c}\mathbf{A H} \\
\%\end{array}$ & 2008 & $\begin{array}{c}\text { AV } \\
\% \\
\end{array}$ & AH\% \\
\hline ATIVO & 3.761 & 100 & 178 & 3.751 & 100 & 177 & 3.554 & 100 & 168 & 2.116 & 100 & 100 \\
\hline Circulante & 1.297 & 34 & 312 & 464 & 12 & 112 & 472 & 13 & 114 & 415 & 20 & 100 \\
\hline Disponível & 16 & 0,5 & 345 & 21 & 0,6 & 448 & 32 & 1 & 673 & 4 & 0,2 & 100 \\
\hline Créditos & 170 & 4 & 152 & 114 & 3 & 103 & 117 & 3 & 105 & 112 & 5 & 100 \\
\hline Estoques & 6 & 0,2 & 116 & 6 & 0,2 & 105 & 6 & 0,2 & 105 & 6 & 0,3 & 100 \\
\hline Outros & 1.100 & 29 & 488 & 322 & 9 & 774 & 315 & 9 & 580 & 292 & 14 & 100 \\
\hline At.Fin.Conc. & 303 & 0,1 & 100 & 303 & 0,1 & 100 & 302 & 0,1 & - & - & - & - \\
\hline Cta.Res.Comp. & 797 & 0,2 & - & - & - & - & - & - & - & - & - & - \\
\hline Não Circulante & 2.464 & 65 & 145 & 3.286 & 88 & 193 & 3.081 & 87 & 181 & 1.701 & 80 & 100 \\
\hline RLP & 1.701 & 45 & 187 & 2.520 & 67 & 277 & 2.284 & 64 & 251 & 909 & 43 & 100 \\
\hline Investim. & 317 & 8 & 138 & 297 & 8 & 129 & 279 & 8 & 122 & 230 & 11 & 100 \\
\hline Imobilizado & 441 & 12 & 79 & 467 & 12 & 83 & 516 & 14 & 92 & 559 & 26 & 100 \\
\hline Intangível & 2 & 0,1 & 243 & 1 & 0,1 & 143 & 1 & 0,1 & 106 & 1 & 0,1 & 100 \\
\hline PASSIVO & 3.763 & 100 & 178 & 3.753 & 100 & 177 & 3.555 & 100 & 168 & 2.116 & 100 & 100 \\
\hline Circulante & 609 & 16 & 139 & 476 & 13 & 109 & 438 & 12 & 100 & 437 & 21 & 100 \\
\hline Não Circulante & 984 & 26 & 90 & 1.224 & 33 & 112 & 1.227 & 34 & 112 & 1.097 & 52 & 100 \\
\hline PL & 2.169 & 58 & 373 & 2.052 & 55 & 353 & 1.890 & 53 & 325 & 581 & 27 & 100 \\
\hline
\end{tabular}

Fonte: Adaptado pelos autores a partir das Demonstrações Contábeis da CEEE-GT.

Tabela 6: Demonstração dos Resultados dos Exercícios da CEEE-GT, período de 2008-201. Milhão de Reais

\begin{tabular}{l|c|c|c|c|c|c|c|c|c|c|c|c}
\hline DRE & $\mathbf{2 0 1 1}$ & $\begin{array}{c}\text { AV } \\
\mathbf{\%}\end{array}$ & $\begin{array}{c}\text { AH } \\
\mathbf{\%}\end{array}$ & $\mathbf{2 0 1 0}$ & $\begin{array}{c}\text { AV } \\
\mathbf{\%}\end{array}$ & $\begin{array}{c}\text { AH } \\
\mathbf{\%}\end{array}$ & $\mathbf{2 0 0 9}$ & $\begin{array}{c}\text { AV } \\
\mathbf{\%}\end{array}$ & $\begin{array}{c}\text { AH } \\
\mathbf{\%}\end{array}$ & $\mathbf{2 0 0 8}$ & $\begin{array}{c}\text { AV } \\
\mathbf{\%}\end{array}$ & $\begin{array}{c}\text { AH } \\
\mathbf{\%}\end{array}$ \\
\hline Rec. de Venda Bens/Serv. & 762 & 100 & 128 & 738 & 100 & 124 & 720 & 100 & 121 & 597 & 100 & 100 \\
\hline Custo Bens/ Serv. Vend. & -415 & -54 & 161 & -440 & -60 & 171 & -359 & -50 & 140 & -257 & -43 & 100 \\
\hline Result. Bruto & $\mathbf{3 4 7}$ & 46 & 102 & $\mathbf{2 9 7}$ & 40 & 88 & $\mathbf{3 6 0}$ & 50 & 106 & $\mathbf{3 4 0}$ & 57 & 100 \\
\hline Desp./Rec. Operac. & -213 & -28 & 190 & -220 & -30 & 196 & 967 & 134 & 859 & -112 & -19 & 100 \\
\hline
\end{tabular}




\begin{tabular}{l|r|r|r|r|r|r|r|r|r|c|c|c}
\hline $\begin{array}{l}\text { Result. Antes Result. } \\
\text { Financ. e Trib. }\end{array}$ & $\mathbf{1 3 3}$ & $\mathbf{1 8}$ & $\mathbf{5 9}$ & $\mathbf{7 6}$ & $\mathbf{1 0}$ & $\mathbf{3 4}$ & $\mathbf{1 . 3 2 8}$ & $\mathbf{1 8 4}$ & $\mathbf{5 8 4}$ & $\mathbf{2 2 7}$ & $\mathbf{3 8}$ & $\mathbf{1 0 0}$ \\
\hline Desp./Rec. Financ. & -30 & -4 & 49 & 29 & 4 & 47 & -28 & -4 & 45 & -61 & -10 & 100 \\
\hline $\begin{array}{l}\text { Result. Antes Trib. s/ } \\
\text { Lucro }\end{array}$ & $\mathbf{1 0 3}$ & 14 & 62 & $\mathbf{1 0 6}$ & 14 & 64 & $\mathbf{1 . 2 9 9}$ & 180 & 782 & $\mathbf{1 6 6}$ & 28 & 100 \\
\hline IR e CS s/ Lucro & -15 & -2 & 36 & 46 & 6 & 110 & 43 & 6 & 104 & -42 & -7 & 100 \\
\hline Lucro/Prej. do Período & $\mathbf{8 8}$ & 12 & 71 & $\mathbf{1 5 2}$ & 21 & 123 & $\mathbf{1 . 3 4 3}$ & 186 & 1084 & $\mathbf{1 2 3}$ & 21 & 100 \\
\hline
\end{tabular}

Fonte: Adaptado pelos autores a partir das Demonstrações Contábeis da CEEE-GT.

\section{- Análise das Demonstrações Contábeis do período de 2008 a 2011}

Salienta-se que a análise horizontal realizada foi a encadeada, considerada por Matarazzo (2010, p.174) como aquela que "pode ser efetuada através do cálculo das variações em relação a um ano base." Em termos nominais, verifica-se evolução do Ativo de 78\% comparando-se o ano de 2008 a 2011. O subgrupo Circulante apresenta um acréscimo de $212 \%$ no mesmo período. Observe-se que esse deriva do processo ordinário $\mathrm{n}^{\circ}$ 93.00.02153-2, movido pela CEEE-GT contra a União, relativo à complementação e suplementação de aposentadoria de seus empregados ex-autárquicos, com suas respectivas correções monetárias e juros moratórios dos exercícios de 1981 a 1993.

Já o subgrupo Não Circulante apresentou uma desaceleração no crescimento que vinha apresentando, pois partiu de uma evolução de 81\% (2008-2009) reduzindo para 45\% (20082011). Essa queda refere-se ao subgrupo Realizável em Longo Prazo, onde houve a reclassificação do direito reconhecido na "Conta Resultados a Compensar" para o Ativo Circulante, em função da decisão favorável do Superior Tribunal de Justiça - STJ (RESP ${ }^{\circ}$ 435.948-RS).

No ano de 2009 houve o reconhecimento global da receita no resultado, impactando no lucro líquido desse exercício e originando o reconhecimento do direito no RLP. Nesse contexto a Concessionária teve definitivamente reconhecido pelo poder judiciário um valor a receber líquido de $\mathrm{R} \$ 1.153 .631$ os quais serão pagos pela União mediante a emissão de Notas do Tesouro Nacional - NTN.

No que se refere ao Ativo Imobilizado observa-se uma redução de $12 \%$ em seu valor do ano 2008 para 2009, isso ocorreu em virtude da observância da Lei 11.368/2007, que gerou uma reclassificação de contas do ativo imobilizado para bens e direitos destinados a alienação e bens de renda, no ativo circulante. Esta mesma Lei criou o subgrupo Intangível que no momento é pouco representativo no subgrupo Não Circulante. 
Além desses aspectos, cabe salientar que os valores relativos ao Imposto de Renda e Contribuição Social sobre o lucro, constantes na DRE, nos anos de 2010 e 2011, respectivamente, referem-se a reclassificações de valores relativos aos depósitos judiciais e provisões para contingências trabalhistas, cíveis e tributárias; e reclassificação dos valores relativos a imposto de renda e contribuição social diferidos do passivo circulante para o passivo não circulante; conforme descritos nas notas explicativas da CEEE-GT.

$\mathrm{Na}$ análise da DRE verifica-se o incremento de 28\% na Receita Bruta ao longo do período em estudo. No entanto, a empresa apresenta uma redução do lucro bruto de 2009 para 2010 (106 para 88\%), porém em 2011 apresentou uma recuperação (88 para 102\%). Isso se deveu ao fato de que a empresa trabalha com um custo elevado, em torno de $50 \%$ da receita, e que apresentou uma evolução constante no período, chegando a um acréscimo de 61\%. Depreende-se, então, que os custos tem apresentado uma evolução maior que as receitas.

Os referidos custos, agregados às despesas operacionais reduzem o resultado para $12 \%$. Com relação à evolução dos resultados, verifica-se uma queda acentuada no resultado operacional. Chama-se a atenção para as despesas/receitas operacionais que constantemente apresentam um resultado negativo, exceto no ano de 2009, afetado pelo processo ordinário $\mathrm{n}^{\circ}$ 93.00.02153-2, descrito anteriormente.

\section{- Análise Econômica e Financeira}

Na Tabela 7 estão dispostos os índices que serviram de base para a análise financeira, composta pelos índices de estrutura de capital, liquidez, rentabilidade e prazos médios.

Tabela 7: Índices Econômicos e Financeiros, período 2008-2011

\begin{tabular}{|c|c|c|c|c|c|}
\hline ÍNDICE & FÓRMULA & 2011 & 2010 & 2009 & 2008 \\
\hline \multicolumn{6}{|l|}{ ESTRUTURA DE CAPITAL } \\
\hline \multicolumn{6}{|l|}{ Endividamento } \\
\hline Participação de Capital de Terceiros & $\mathrm{CT} / \mathrm{PL}$ & $73 \%$ & $83 \%$ & $88 \%$ & $88 \%$ \\
\hline Composição do Endividamento & $\mathrm{PC} / \mathrm{CT}$ & $38 \%$ & $28 \%$ & $26 \%$ & $29 \%$ \\
\hline \multicolumn{6}{|l|}{ Imobilizações } \\
\hline Imobilização do Patrimônio Líquido * & $\mathrm{AP}+\mathrm{RLP} / \mathrm{PL}$ & $114 \%$ & $160 \%$ & $163 \%$ & $156 \%$ \\
\hline Imobilização de Recursos Não Correntes * & $\mathrm{AP}+\mathrm{RLP} /(\mathrm{PL}+\mathrm{PNC})$ & $78 \%$ & $100 \%$ & $99 \%$ & $83 \%$ \\
\hline \multicolumn{6}{|l|}{ ÍNDICES DE LIQUIDEZ } \\
\hline Liquidez Geral & $\mathrm{AC}+\mathrm{RLP} / \mathrm{PC}+\mathrm{ELP}$ & 1,88 & 1,75 & 1,65 & 0,86 \\
\hline Liquidez Corrente & $\mathrm{AC} / \mathrm{PC}$ & 2,13 & 0,97 & 1,07 & 0,95 \\
\hline Liquidez Seca & $\mathrm{AC}-\mathrm{E} / \mathrm{PC}$ & 2,11 & 0,96 & 1,06 & 0,93 \\
\hline
\end{tabular}




\begin{tabular}{l|c|c|c|c|c}
\hline ÍNDICES DE RENTABILIDADE & & & & & \\
\hline Giro do Ativo & V/AT & 0,20 & 0,19 & 0,20 & 0,28 \\
\hline Margem Líquida & LL/V & $12 \%$ & $21 \%$ & $187 \%$ & $21 \%$ \\
\hline Rentabilidade do Ativo * & LL/AT & $3 \%$ & $3 \%$ & $39 \%$ & $9 \%$ \\
\hline Rentabilidade do Patrimônio Líquido & LL/PL & $4 \%$ & $8 \%$ & $71 \%$ & $21 \%$ \\
\hline PRAZOS MÉDIOS & & & & & \\
\hline Recebimento de Vendas (dias) & (DR/V) x 360 & 46 & 42 & 45 & 48 \\
\hline Renovação dos Estoques (dias) & (E/CMV) x 360 & 6 & 5 & 6 & 8 \\
\hline Pagamento de Compras (dias) & (F/CO) x 360 & 85 & 83 & 73 & 57 \\
\hline Ciclo Operacional (dias) & PMRV+PMRE & 52 & 47 & 51 & 56 \\
\hline Ciclo Financeiro (dias) & PMRV + PMRE - PMPC & -33 & -36 & -22 & -1 \\
\hline \multicolumn{1}{c|}{ Fonte: Elaborado pelos autores. } & & & &
\end{tabular}

$\mathrm{Na}$ formulação dos índices adaptaram-se os índices de imobilizações, onde se considerou, além dos subgrupos que comporiam o Ativo Permanente (Investimento, Imobilizado, Intangível) o subgrupo Realizável em Longo Prazo. Outra adaptação que se fez necessária, foi sobre o índice de rentabilidade do Ativo (*), o qual divide o Lucro Líquido Ajustado pelo Ativo. O lucro utilizado no cálculo desse índice foi obtido mediante a diferença entre o lucro operacional e o Imposto de Renda e Contribuição Social, desconsiderando os efeitos do resultado financeiro.

A CEEE-GT apresenta uma situação confortável em relação a sua composição de capital, tendo em vista a prevalência do capital próprio sobre o de terceiros, este último apresentou um decréscimo nos últimos anos, chegando a 73\% em 2011. No tocante ao endividamento da empresa, observa-se que se dá em maior parte em Longo Prazo. Outro aspecto a salientar, é o fato de que a empresa vem aplicando a maior parte dos recursos próprios (PL) e não correntes (PNC) no Ativo Não Circulante, que envolve o Realizável em Longo Prazo e o antigo Ativo Permanente, hoje representado pelo somatório dos subgrupos Investimentos, Imobilizado e Intangível.

A empresa apresenta uma folga financeira, ou seja, possui um excedente de $\mathrm{R} \$ 0,88$ para cada $\mathrm{R} \$ 1,00$ de dívida, o que se enfatiza na liquidez corrente, onde a folga financeira passa para $\mathrm{R} \$ 1,13$, em 2011 e se reforça ainda mais na liquidez seca, que apresenta uma folga de $\mathrm{R} \$ 1,11$, evidenciando que os estoques representam em torno de $0,02 \%$ na liquidez demonstrando que a empresa independe dos seus estoques para saldar suas dívidas.

Observou-se piora nos resultados de rentabilidade, tanto no que se refere ao retorno do Patrimônio Líquido, como no que tange ao Retorno do Ativo Ajustado. Em 2008 o retorno do PL atingiu 21\%, decaindo para 4\% em 2011, enquanto que o Retorno do Ativo passou de $9 \%$ em 
2008, para 3\% em 2011. A empresa gerencia adequadamente seus prazos de recebimentos e de pagamentos. Em média os recebimentos retornam em torno de 46 dias em decorrência das vendas realizadas a prazo, enquanto os pagamentos a seus fornecedores ocorrem em 85 dias, gerando uma significativa folga financeira nesse período. Verifica-se que o ciclo operacional da empresa é de 52 dias, que é o tempo ocorrido entre a compra (nesse caso geração de energia) a venda e o respectivo recebimento dessa comercialização. Isso gera um ciclo financeiro de - 33 dias, o que representa que a empresa gera energia, vende e recebe 33 dias antes de realizar os pagamentos aos seus fornecedores.

\subsection{Indicadores Socioambientais}

A empresa, além das demonstrações contábeis, elabora e publica o Balanço Social, utilizando o modelo do Instituto Brasileiro de Análises Sociais e Econômicas - IBASE. Com base neste balanço e na DVA pode-se delinear o perfil socioambiental da empresa.

\section{- Análise da Demonstração do Valor Adicionado}

Apresenta-se, a seguir, na tabela 8, a análise vertical da DVA da CEEE-GT.

Tabela 8: Análise Vertical da Demonstração do Valor Adicionado, período 2008-2011. Milhão de Reais.

\begin{tabular}{l|c|c|c|c|c|c|c|c}
\hline Descrição & $\mathbf{2 0 1 1}$ & $\mathbf{\%}$ & $\mathbf{2 0 1 0}$ & $\mathbf{\%}$ & $\mathbf{2 0 0 9}$ & $\mathbf{\%}$ & $\mathbf{2 0 0 8}$ & $\mathbf{\%}$ \\
\hline Receitas & 921.040 & $\mathbf{1 0 0}$ & 850.079 & $\mathbf{1 0 0}$ & 1.973 .741 & $\mathbf{1 0 0}$ & 693.703 & $\mathbf{1 0 0}$ \\
\hline Insumos adquiridos de 3 $^{\mathbf{0}}$ & -330.465 & -36 & -239.105 & -28 & -200.438 & -10 & -98.413 & -14 \\
\hline Valor Adicionado Bruto & $\mathbf{5 9 0 . 5 7 5}$ & $\mathbf{6 4}$ & $\mathbf{6 1 0 . 9 7 4}$ & $\mathbf{7 2}$ & $\mathbf{1 . 7 7 3 . 3 0 3}$ & $\mathbf{9 0}$ & $\mathbf{5 9 5 . 2 9 0}$ & $\mathbf{8 6}$ \\
\hline Retenções & -48.090 & -5 & -168.829 & 20 & -103.562 & -5 & -46.690 & -7 \\
\hline V. A. Líquido Produzido & $\mathbf{5 4 2 . 4 8 5}$ & 59 & $\mathbf{4 4 2 . 1 4 5}$ & 52 & $\mathbf{1 . 6 6 9 . 7 4 1}$ & 85 & $\mathbf{5 4 8 . 6 0 0}$ & 79 \\
\hline VA. Recebido em Transf. & $\mathbf{9 7 . 7 4 2}$ & 10 & $\mathbf{- 1 3 1 . 2 9 6}$ & 15 & $\mathbf{1 1 7 . 8 6 4}$ & 6 & $\mathbf{6 9 . 7 9 4}$ & 10 \\
\hline V. A. Total a Distribuir & $\mathbf{6 4 0 . 2 2 7}$ & $\mathbf{6 9}$ & $\mathbf{5 7 3 . 4 4 1}$ & $\mathbf{6 7}$ & $\mathbf{1 . 7 8 7 . 6 0 5}$ & $\mathbf{9 1}$ & $\mathbf{6 1 8 . 3 9 4}$ & $\mathbf{8 9}$ \\
\hline Distribuição do V. A. & $\mathbf{6 4 0 . 2 2 7}$ & $\mathbf{1 0 0}$ & $\mathbf{5 7 3 . 4 4 1}$ & $\mathbf{1 0 0}$ & $\mathbf{1 . 7 8 7 . 6 0 5}$ & $\mathbf{1 0 0}$ & $\mathbf{6 1 8 . 3 9 4}$ & $\mathbf{1 0 0}$ \\
\hline Pessoal & 256.652 & 40 & 215.519 & 37 & 226.395 & 13 & 191.655 & 31 \\
\hline Imp.Taxas e Contrib. & 179.605 & 28 & 114.923 & 20 & 84.985 & 5 & 165.799 & 27 \\
\hline Remun.de Capitais de 3 & 115.797 & 18 & 90.233 & 16 & 133.125 & 7 & 137.044 & 22 \\
\hline Remun.de Cap. Próprios & 88.173 & 14 & 152.766 & 27 & 1.343 .100 & 75 & 123.896 & 20 \\
\hline Produt. VA do trabalho & 306 & - & 357 & - & 1.145 & - & 407 & - \\
\hline
\end{tabular}

Fonte: Adaptado pelos autores.

A DVA revela a geração e a distribuição da riqueza gerada pela empresa entre aqueles que contribuíram para sua geração. Verifica-se que a CEEE-GT gerou um valor adicionado líquido de R\$ 618.394 milhões em 2008; R\$ 1.787 .605 milhões em 2009; R\$ 573.441 milhões em 2010 e 
R\$ 640.227 milhões em 2011, correspondentes a 89\%, 91\%, 67\% e 69\% de suas receitas, respectivamente.

Verifica-se que, diferentemente das demais empresas do setor elétrico, que distribuem a maior parte da sua riqueza gerada para o Governo, a CEEE - GT tem como maior detentor da sua riqueza o Pessoal, envolvendo salários, encargos trabalhistas, entre outros. Essa situação ocorre em virtude da CEEE-GT desenvolver apenas as atividades de geração e transmissão de energia, não realizando a comercialização, o que nesse caso refletiria na distribuição do valor adicionado em maior proporção para o governo, conforme leitura da empresa CEEE-D, não objeto deste artigo.

A remuneração dos capitais de terceiros apresentou uma queda ao longo de 2009 e 2010, mas apresenta um aumento em 2011, sinalizando um incremento no endividamento da empresa com terceiros. Já a remuneração dos sócios e acionistas apresentou queda ao longo dos anos, exceto no ano de 2009, que, influenciado pelo processo já mencionado no item 4.2, apresentou uma expressiva distribuição da riqueza entre os sócios e acionistas.

De forma complementar à análise da DVA, calculou-se o indicador estabelecido por Tinoco (2010), denominado "Produtividade de valor adicionado do trabalho", obtido mediante a divisão do valor adicionado bruto pelo número médio de funcionários da empresa no ano, considerando os servidores efetivos, terceirizados e estagiários. Esse indicador reflete o montante que cada funcionário contribui na geração do valor adicionado. Em 2011 o valor adicionado por empregado foi de R\$ 306 mil, em 2010 R\$ 357 mil, em 2009 R\$ 1.145 mil e em 2008 R\$ 407. A análise desses dados permite concluir que o valor adicionado gerado por cada empregado tem diminuído ao longo do tempo, exceto no ano de 2009 , que teve o resultado afetado pelo processo judicial citado no item 4.2.

\section{- Análise do Balanço Social}

$\mathrm{Na}$ análise dos indicadores do Balanço Social da CEEE-GT do ano de 2011, destaca-se a alocação de recursos nos elementos sociais externos, que representam $65 \%$ do resultado operacional. Já os indicadores sociais internos representam $46 \%$ da folha de pagamento bruta e $12 \%$ da receita líquida. Os investimentos em meio ambiente representam 5\% do resultado operacional. 
Os indicadores sociais internos revelam que os encargos sociais compulsórios, os benefícios concedidos aos colaboradores e a previdência privada são os fatores que possuem maior representatividade sobre a receita operacional líquida. Percebe-se também que houve um crescimento no valor investido em medicina e segurança chegando, em 2011 a R\$ 988 mil reais, o que reflete na redução do número de acidentes de trabalho, oito acidentes em 2008, dez em 2009, 7 em 2010 e três em 2011, fruto da política de investimento em segurança do trabalho da CEEE-GT. O estabelecimento dos padrões de segurança e salubridade no ambiente de trabalho ocorreu com a participação de todos os funcionários e também da Comissão Interna de Prevenção de Acidentes - CIPA.

Nos indicadores sociais externos realçam-se os investimentos em educação e cultura. Os investimentos em gestão dos recursos ambientais destacam-se no plano de gestão Sócio Patrimonial e Ambiental. Seguidamente, os investimentos nos Programas Ambientais se sobressaem no programa de poda e desmatamento e também na manutenção de faixas de servidão.

Com relação ao corpo funcional da empresa verifica-se uma evolução no número de empregados, decorrente de admissões. Observando-se as informações de 2011 e 2010, nota-se que o número de empregados variou positivamente em 61 empregados, considerando-se o número de contratações (107) conclui-se que 46 empregados foram desligados da empresa. Outro ponto relevante é o grande número de contratações de empregados terceirizados no ano de 2011. A empresa não possuía nenhum empregado terceirizado até o ano de 2010, no entanto terminou o ano de 2011 com 439 empregados, sinalizando uma mudança na política de gestão de pessoas.

Observa-se que o quadro de pessoal acima de 45 anos vem se mantendo ao longo do tempo, representando em média $41 \%$, portanto a empresa demonstra que os desligamentos ocorridos no período referem-se ao pessoal de outra faixa etária. No que se refere ao número de mulheres que trabalham na empresa, observa-se que a empresa mantém evolução do quadro de pessoal por sexo estável, onde as mulheres representam 17\%. Chama a atenção para o fato de que a CEEE-GT é uma sociedade de economia mista e por isso possui um processo de seleção pública através de concurso público, o que nesse sentido não impediria que mais mulheres ingressassem no quadro de pessoal.

Observa-se que a CEEE-GT até o ano de 2009 não evidenciava o número de negros 
integrantes do seu quadro de pessoal, pois não considerava distinção étnica na evidenciação da composição do quadro funcional. Nos anos de 2010 e 2011, a empresa revela ter respectivamente 174 e 175 negros em seu quadro funcional, que ocupam em média 8\% dos cargos de chefia. Desde o ano de 2009, os portadores de deficiências ocupam $2 \%$ do quadro de pessoal. No entanto a Lei $\mathrm{n}^{\circ} 8.213$ de 1991 estabelece que empresas com mais de 1.000 funcionários devam destinar $5 \%$ de seus cargos para os portadores de deficiências.

No ano de 2008, a relação entre a maior e a menor remuneração era de 7,54, nos demais anos passou para 9,86, o que demonstra um aumento salarial de 2008 para 2009, e a partir desse momento esta relação mantém-se neste percentual. Os demais benefícios concedidos aos empregados (alimentação, creches, previdência privada e planos de saúde) representam 22\% da folha de pagamento bruta. Outro aspecto relacionado à remuneração, é que todos os funcionários participam dos resultados. A empresa descreve em suas notas explicativas que possui um programa de participações de resultados cujo objetivo é incentivar a melhoria de qualidade, níveis de produtividade e resultados globais da empresa. O montante contabilizado em 2011 totalizou $\mathrm{R} \$ 6.039$, tendo sido distribuído o montante de $\mathrm{R} \$ 2.957$ durante o exercício.

No que tange aos direitos laborais, a empresa segue as normas da Organização Internacional do Trabalho - OIT. No que se refere ao grau de instrução, a maioria dos empregados da CEEE-GT (em torno de 60\%) possuem ensino médio completo e em média 30\% possuem graduação. Verificou-se que os gastos com educação, capacitação e desenvolvimento profissional não chegam a $1 \%$ da folha de pagamento bruta.

Salienta-se que no ano de 2009, somente 4,23\% da Distribuição do Valor Adicionado foi destinado ao governo, pois houve uma antecipação de tutela obtida em sede de liminar na ação do REIDI - Regime Especial de Incentivos para o Desenvolvimento da Infraestrutura, a qual permitiu a desoneração tributária para as empresas do setor elétrico na construção de obras de infraestrutura.

\section{CONSIDERAÇÕES FINAIS}

O objetivo geral dessa pesquisa foi analisar o desempenho econômico, financeiro, social e ambiental da CEEE-GT no período de 2008 a 2011, por meio de suas Demonstrações Contábeis, do Relatório de Administração e do Balanço Social, modelo IBASE. 
Em linhas gerais, a CEEE-GT apresenta desempenho econômico e financeiro satisfatório, de acordo com indicadores evidenciados neste estudo. A estrutura de capital da empresa é boa, tendo em vista a prevalência do capital próprio sobre o de terceiros, que representa 73\% em 2011.

Outro aspecto relevante é o endividamento da empresa que ocorre, na maior parte, em Longo Prazo, 62\%. Isso reflete na folga financeira apresentada, pois se verificou um excedente de $\mathrm{R} \$ 0,88$ de recursos financeiros disponíveis para cada $\mathrm{R} \$ 1,00$ de dívida total contraída. Essa relação se reforça nas dívidas de curto prazo, onde a folga financeira passa para $\mathrm{R} \$ 1,13$, em 2011 e perdura, ainda mais, desconsiderando os estoques, onde se identifica uma folga de R\$ 1,11, demonstrando que a empresa independe dos seus estoques para saldar suas dívidas.

Provavelmente essa folga financeira observada seja fruto da boa gerência dos prazos de recebimentos e pagamentos da empresa, que leva, em torno, de 46 dias para receber as vendas realizadas a prazo e desembolsa seus fornecedores em 85 dias, gerando uma significativa folga financeira nesse período. A empresa realiza seu ciclo operacional em 52 dias, gerando um ciclo financeiro de 33 dias, o que contribui para a manutenção do capital de giro. Observou-se piora nos resultados de rentabilidade, tanto no que se refere ao retorno do Patrimônio Líquido, como no que tange ao Retorno do Ativo Ajustado. Em 2008 o retorno do PL atingiu 21\%, decaindo para 4\% em 2011, enquanto que o Retorno do Ativo passou de 9\% em 2008, para 3\% em 2011. Com relação ao desempenho social e ambiental, a CEEE-GT gerou um valor adicionado líquido de R \$ 618.394 milhões em 2008; R \$ 1.787 .605 bilhões em 2009; R \$ 573.441 milhões em 2010 e R\$ 640.227 milhões em 2011; neste ano distribuiu da riqueza criada 28\% para o Governo, $40 \%$ para os Colaboradores, $14 \%$ para os Acionistas e $18 \%$ para Terceiros. Observou-se que o maior detentor da riqueza gerada foram os colaboradores, envolvendo os gastos com salários, encargos trabalhistas, entre outros. Na análise dos indicadores do Balanço Social da CEEE-GT do ano de 2011, destaca-se o investimento nos elementos sociais externos (educação e cultura e gestão dos recursos ambientais), que representam $65 \%$ do resultado operacional. Já os indicadores sociais internos representam $46 \%$ da folha de pagamento bruta e $12 \%$ da receita líquida, destacando-se os encargos sociais compulsórios, os benefícios concedidos aos colaboradores e a previdência privada. Os investimentos em meio ambiente, pertencentes aos indicadores internos, representam $5 \%$ do resultado operacional. Por meio dessa pesquisa foi possível observar que a CEEE-GT apresenta uma boa gestão de seus recursos econômicos e financeiros, tendo em vista sua 
atividade econômica ser a geração e transmissão de energia às distribuidoras, não sendo responsável, portanto, pela comercialização para o consumidor final. Além disso, demonstra também uma boa gestão social e ambiental considerando-se as informações de seu Balanço Social.

Este estudo limitou-se à análise das informações contidas nas demonstrações contábeis, no relatório da administração e no balanço social da empresa CEEE-GT (geração e transmissão), não abrangendo a atividade de distribuição. Outra limitação que deve ser pontuada é de que não há divulgação quanto à formação de ativos e sua atualização monetária na empresa, como bem explicitam Martins et al. (2012), que se constituem em informações relevantes que podem alterar os valores por ora apresentados. Como recomendações sugere-se para futuras pesquisas a inclusão da CEEE-D (distribuição) para uma análise completa da sua cadeia de valor.

\section{REFERÊNCIAS}

ANEEL. Agência Nacional de Energia Elétrica. Institucional. Disponível em: http://www.aneel.gov.br/. Acesso em: 06 abr. 2012.

ASSAF NETO, Alexandre. Estrutura e análise de balanços: um enfoque econômico-financeiro. 9. ed. São Paulo: Atlas, 2010.

BOVESPA. Companhia Estadual de Geração e Transmissão de Energia Elétrica - CEEE-GT. Disponível em: $\quad$ http://www.bmfbovespa.com.br/Cias-Listadas/EmpresasListadas/ResumoEmpresaPrincipal.aspx?codigoCvm=3204\&idioma=en-us. Acesso em: 06 abr. 2012.

BRASIL. Constituição (1988). Constituição da República Federativa do Brasil: promulgada em 5 de outubro de 1988: atualizada até a Emenda Constitucional n.62, de 9-12-2009. Vade Mecum. 9.ed.atual.e ampl. São Paulo: Saraiva, 2010.

BRASIL. Lei no 6.404 de 15 de dezembro de 1976 - Dispõe sobre as Sociedades por Ações. Disponível em: http://www.planalto.gov.br/ccivil_03/LEIS/L6404consol.htm. Acesso em: 07 jun. 2012.

BRASIL. Lei $\mathrm{n}^{\mathrm{o}} 11.638$ de 28 de dezembro de 2007 - Altera e revoga dispositivos da Lei $\mathrm{n}^{\mathrm{o}}$ 6.404, de 15 de dezembro de 1976, e da Lei $\mathrm{n}^{-0}$ 6.385, de 7 de dezembro de 1976, e estende às sociedades de grande porte disposições relativas à elaboração e divulgação de demonstrações financeiras. Disponível em: http://www.planalto.gov.br/ccivil_03/_ato20072010/2007/lei/111638.htm. Acesso em: 07 jun. 2012.

CARNEIRO, José Eliano; DE LUCA, Márcia Martin Mendes; OLIVEIRA, Marcelle Colares. 
Análise das informações ambientais evidenciadas nas demonstrações financeiras das empresas petroquímicas brasileiras listadas na Bovespa. Revista Contabilidade Vista e Revista. Vol. 19, n.3 Jul./Set. 2008.

CASTRO, Roberto; LYRA FILHO, Christiano. Um método de suporte a decisões sobre investimento e comercialização de energia elétrica no Brasil. Revista da Sociedade Brasileira de Automática - Controle \& Automação. Campinas, vol.16 n.4, out/dez 2005. Disponível em: http://www.scielo.br/scielo.php?script=sci_arttext\&pid=S0103-17592005000400008\&lang=pt. Acesso em: 30 jun. 2012.

CEEE. Companhia Estadual de Energia Elétrica. História do Grupo CEEE. Disponível em: http://www.ceee.com.br/pportal/ceee/Component/Controller.aspx?CC=3237. Acesso em: 13 abr.2012.

CUNHA, Jacqueline Veneroso Alves da; RIBEIRO, Maísa de Souza; SANTOS, Ariovaldo dos. A demonstração do valor adicionado como instrumento de mensuração da distribuição da riqueza. Revista Contabilidade e Finanças. São Paulo. vol.16 n.37, jan./abr. 2005. Disponível em: $\quad$ http://www.scielo.br/scielo.php?script=sci arttext\&pid=S151970772005000100001\&lang=pt. Acesso em: 01 jul. 2012.

GIL, Antônio Carlos. Métodos e Técnicas de Pesquisa Social. 5. ed. São Paulo: Atlas, 1999.

IBASE. Instituto Brasileiro de Análises Sociais e Econômicas. Institucional. Disponível em: http://www.ibase.br/pt/. Acesso em: 07 jul. 2012.

IUDÍCIBUS, Sérgio de; MARTINS, Eliseu; GELBCKE, Ernesto Rubens; SANTOS, Ariovaldo dos. Manual de Contabilidade Societária: aplicável a todas as Sociedades de acordo com as Normas Internacionais e do CPC. São Paulo: Atlas, 2010.

DE LUCA, Márcia Martins Mendes. Demonstração do Valor Adicionado: do cálculo da riqueza criada pela empresa ao valor do PIB. São Paulo: Atlas, 1998.

MARTINS, Eliseu. Balanço social - ideia que merece permanecer. Gazeta Mercantil, São Paulo - SP, p. A-3, 18 set. 1997.

MARTINS, Eliseu; DINIZ, Josedilton Alves; MIRANDA, Gilberto José. Análise Avançada das Demonstrações Contábeis. São Paulo: Atlas, 2012.

MATARAZZO, Dante Carmine. Análise financeira de balanços: abordagem gerencial. 7. ed. São Paulo: Atlas, 2010.

MELO NETO, Francisco P. de; FROES, César. Gestão da responsabilidade social corporativa: o caso brasileiro. Rio de Janeiro: Qualitymark, 2001.

PINTO, Anacleto Laurino; RIBEIRO, Maísa de Souza. Balanço social: avaliação de informações fornecidas por empresas industriais situadas no estado de Santa Catarina. São Paulo. Revista Contabilidade e Finanças, v. 15, n. 36, set/dez 2004. Disponível em: 
http://www.scielo.br/scielo.php?script=sci arttext\&pid=S1519-70772004000300002\&lang=pt. Acesso em: 01 jul 2012.

RAUPP, Fabiano Maury; BEUREN, Ilse Maria. Metodologia da pesquisa aplicável às ciências sociais. In: BEUREN, Ilse Maria (org.). Como elaborar trabalhos monográficos em contabilidade: teoria e prática. 3. ed. São Paulo: Atlas, 2006.

RIBEIRO, Maísa de Souza. Contabilidade e meio ambiente. 1992. 141 f. Dissertação (Mestrado Contabilidade e Controladoria) - Faculdade de Economia, Administração e Contabilidade, Universidade de São Paulo, São Paulo, 1992.

SANT'ANNA, Paulo Roberto de; et al. Tecnologia da informação como ferramenta para a análise econômica e financeira em apoio à tomada de decisão para as micro e pequenas empresas. Revista de Administração Pública. Rio de Janeiro, v. 45, n. 5, set/out 2011. Disponível em: http://www.scielo.br/scielo.php?script=sci arttext\&pid=S0034-76122011000500015\&lang=pt. Acesso em: 30 jun. 2012.

SANTOS, Ariovaldo dos. Demonstração do Valor Adicionado: como elaborar e analisar a DVA. São Paulo: Atlas, 2003.

TINOCO, João Eduardo Prudêncio. Balanço Social: uma abordagem socioeconômica da contabilidade. 1984. Dissertação (Mestrado) - Faculdade de Economia, Administração e Contabilidade, Universidade de São Paulo, São Paulo, 1984.

TINOCO, João Eduardo Prudêncio. Balanço Social e o Relatório da Sustentabilidade. São Paulo: Atlas, 2010.

WARREN, Carl S.; REEVE, James M.; FESS, Philip E. Contabilidade Gerencial. Tradução de André Olimpio M. Du C. Castro. 2. ed. São Paulo: Thomson Learning, 2008. 